\title{
Image Guidance of Pleural Biopsies: Are Electromagnetic Waves Superior to Sound Waves?
}

\author{
Coenraad F.N. Koegelenberg Brian W. Allwood \\ Division of Pulmonology, Department of Medicine, Stellenbosch University and Tygerberg Academic Hospital, \\ Cape Town, South Africa
}

Pleural exudates that remain undiagnosed despite pleural fluid analysis are a common clinical problem. Yet, the most efficient and cost-effective approach is still not well established. In situations where thoracocentesis is non-diagnostic, many authorities favour thoracoscopy as the investigation of choice, particularly if malignancy is suspected [1]. Protagonists of such an approach give support to thoracoscopy by citing reasons such as superior diagnostic yield, relative safety and the ease of talc poudrage under direct vision if needed. However, medical thoracoscopy requires a degree of expertise often not available outside tertiary referral centres, thus limiting its widespread adoption [2].

On the other hand, image-assisted closed pleural biopsies can be performed in most medical facilities, therefore potentially offering a more rapid, accessible and cost-effective alternative to thoracoscopy [3]. Imaging, using both computed tomography (CT) and transthoracic ultrasound guidance, has been added to previous 'blind' techniques, allowing for directed and therefore more accurate biopsy of abnormal pleura. Image guidance has been shown to increase the likelihood of obtaining diagnostic pleural tissue independent of the presence of pleural thickening, while allowing biopsies to be performed closer to the diaphragm and midline - areas where malig- nant deposits are thought to accumulate more frequently. Similarly, image-assisted biopsies are thought to be safer by decreasing the risk of damage to surrounding visceral tissue [1-3].

Transthoracic ultrasound to guide transthoracic interventions has only been practiced since the late 1980 s, despite being used as a diagnostic modality since the 1940s. The early studies suggested that ultrasound-guided TruCut pleural biopsy had a diagnostic yield of $87 \%$ for all pleural pathologies (77\% for malignancies), irrespective of pleural thickening or nodularity [4]. For malignant mesothelioma of at least $20 \mathrm{~mm}$ in any dimension, this figure is increased to around $100 \%$. Similarly, ultrasoundguided Abrams needle biopsy was shown to have diagnostic yields between $80-90 \%$ for pleural tuberculosis and $83-90 \%$ for pleural malignancies $[5,6]$.

The advent of CT guidance has significantly increased the diagnostic yield in the setting of pleural thickening [7]. Perhaps unsurprisingly, CT-guided cutting needle biopsy was shown to be far superior to unaided Abrams needle biopsy (sensitivity 87 vs. $44 \%, \mathrm{p}=0.02$ ) [7]. Metintas and co-workers [8] previously found CT-guided Abrams needle biopsy to be on par with thoracoscopy. In that study, they randomly assigned 124 patients with effusions not diagnosed by cytology to either Abrams nee-

\section{KARGER}

E-Mail karger@karger.com

www.karger.com/res
(C) 2016 S. Karger AG, Basel

0025-7931/16/0914-0267\$39.50/0
Coenraad F.N. Koegelenberg

Division of Pulmonology, Department of Medicine

Stellenbosch University and Tygerberg Academic Hospital

PO Box 241, Cape Town 8000 (South Africa)

E-Mail coeniefn@sun.ac.za 
dle biopsy guided by CT findings or medical thoracoscopy [8]. The CT-guided pleural biopsy group had a diagnostic sensitivity of $87.5 \%$, compared to $94.1 \%$ in the thoracoscopy group $(p=0.252)$. In cases having at least $1 \mathrm{~cm}$ of pleural thickening, theses sensitivities increased to 95 and $96 \%$, respectively. Reassuringly, the cause of the effusion did not influence these results, and few complications were reported for either technique [8].

In a recent issue of Respiration, Metintas and coworkers [9] report the first randomised prospective study comparing CT-scan-guided pleural biopsy using an Abrams needle with ultrasound-assisted pleural biopsy with a cutting needle with respect to both diagnostic yield and safety. The authors report that CT-guided biopsy has a superior yield ( 82.4 vs. $66.7 \%, p=0.029$ ). Moreover, the sensitivity of CT-guided biopsy increased to $93.7 \%$ in cases with pleural thickness $\geq 1 \mathrm{~cm}$. The authors concluded that CT-guided biopsy should be preferred in patients with pleural effusion and associated pleural thickening.

Does this mean that ultrasound-guided pleural biopsy can no longer be viewed as an alternative to CT-guided biopsy? Before mothballing one's ultrasound machine, there are a few important considerations. Most notably, Metintas et al. [9] compared not only two different imaging modalities, but also the performance of two very different biopsy needle types. In the context of ultrasoundassisted biopsy, Abrams needle biopsy specimens have already been shown to yield more pleural tissue than those obtained using Tru-Cut needles (91.0 vs. 78.7\%, $\mathrm{p}=0.015$ ) [5]. These results may cause one to question whether the current investigators were in fact comparing needle types, imaging modalities or possibly a combination of both. Some more practical aspects also need highlighting. CT scanning remains expensive when compared to transthoracic ultrasound and has the additional disadvantage of exposing patients to ionizing radiation. Further, ultrasound-assisted biopsy can be performed using relatively inexpensive portable ultrasound equipment, and by a single operator at the bedside using minimal monitoring. These advantages, combined with the ability to image patients in the correct anatomical position for biopsy (i.e. sitting) as opposed to using planometric measurements from supine CT images, should not be ignored. A final point of consideration is whether the use of both imaging techniques together would have greater diagnostic yield than either alone. CT images undoubtedly provide the best visualisation of the entire pleural surface and thus biopsy site, while bedside ultrasound may avoid sampling error due to changes in patient posture between CT scan and biopsy positioning. Naturally, potential gains in yield of a dual approach need to be balanced against increased cost.

The present study by Metintas and colleagues [9] once again validates the use of CT-guided Abrams needle biopsy as an alternative to thoracoscopy, particularly in patients with pleural thickening. However, only a randomised study comparing CT-guided and ultrasoundguided biopsy, where only Abrams needles are used, would establish whether CT guidance is truly superior to ultrasound guidance as the imaging modality of choice.

\section{References}

$>1$ Hooper C, Lee YC, Maskell N: Investigation of a unilateral pleural effusion in adults: British Thoracic Society pleural disease guideline 2010. Thorax 2010;65(suppl 2):ii4-ii17.

-2 Koegelenberg CF, Diacon AH: Image-guided pleural biopsy. Curr Opin Pulm Med 2013;19: 368-373.

$>3$ Koegelenberg CF, Diacon AH: Pleural controversy: closed needle pleural biopsy or thoracoscopy - which first? Respirology 2011;16: $738-746$.

$\checkmark 4$ Chang BD, Yang PC, Luh KT, et al: Ultrasound-guided pleural biopsy with Tru-Cut needle. Chest 1991;100:1328-1333.
5 Koegelenberg CF, Bolliger CT, Theron J, et al: Direct comparison of the diagnostic yield of ultrasound-assisted Abrams and Tru-Cut needle biopsies for pleural tuberculosis. Tho$\operatorname{rax} 2010 ; 65: 857-862$.

6 Koegelenberg CF, Irusen EM, von GrooteBidlingmaier F, et al: The utility of ultrasound-guided thoracentesis and pleural biopsy in undiagnosed pleural exudates. Thorax 2015;70:995-997.

7 Maskell NA, Gleeson FV, Davies RJ: Standard pleural biopsy versus CT-guided cutting-needle biopsy for diagnosis of malignant disease in pleural effusions: a randomised controlled trial. Lancet 2003;361:1326-1330.
8 Metintas M, Ak G, Dundar E, et al: Medical thoracoscopy vs CT scan-guided Abrams pleural needle biopsy for diagnosis of patients with pleural effusions: a randomized, controlled trial. Chest 2010;137:1362-1368.

$\checkmark$ Metintas M, Yildirim H, Kaya T, Ak G, Dundar E, Ozkan R, Metintas S: CT scan-guided Abrams' needle pleural biopsy versus ultrasound-assisted cutting needle pleural biopsy for diagnosis in patients with pleural effusion: a randomized, controlled trial. Respiration 2016;91:156-163. 